\title{
Energy Expenditure Differs between Black and White Americans: Implications for Obesity Prevention Research
}

\author{
Nūn Sava-Siva Amen-Ra ${ }^{1}$, Eduardo Velasco-Mondragon ${ }^{2}$, Mian Bazle Hossain ${ }^{1}$, Yvonne Bronner ${ }^{1}$ \\ ${ }^{1}$ School of Community Health and Policy, Morgan State University, Baltimore, USA; ${ }^{2}$ College of Osteopathic Medicine, Touro Uni- \\ versity, Vallejo, USA. \\ Email: Amen-Ra@AmentaEliteAthlete.com
}

Received May $2^{\text {nd }}, 2012$; revised June $4^{\text {th }}, 2012$; accepted June $11^{\text {th }}, 2012$

\begin{abstract}
Objective: To assess differences in energy expenditure by race and ethnicity using nationally representative data. Results: We confirmed that Blacks exhibit lower resting energy expenditure than Whites - a difference of approximately 150 to 300 fewer kilocalories per day. This finding was significant in each permutation of our analysis - from the simple association of race and resting energy expenditure to our final regression model adjusted for common confounders (i.e. age, gender, income, and education), body fat content, diabetes, thyroid dysfunction, and weight loss in previous year. Further, we found that energy intake did not differ significantly between Blacks and Whites whereas Blacks were found to expend significantly more energy voluntarily than Whites. Blacks and Whites did not differ significantly in bodyweight, though Blacks were found to be leaner than Whites as evidenced by significantly lower body fat content in the former. Discussion: Our findings suggest that if rates of obesity are to be reduced in Black Americans, recommendations would need to encourage lower levels of average energy intake and higher levels of activity energy expenditure than extant in the general populace. In short, Blacks would need to adopt more austere lifestyle regimens relative to the general populace in order to reduce their rate of obesity below present levels.
\end{abstract}

Keywords: Resting Metabolic Rate; Race; Caloric Intake; Bodyweight; Exercise

\section{Introduction}

Given the equivalence of mass and energy, an animal's bodyweight reflects its total energy content. Thus, the equilibrium between the amount of energy an animal ingests and the amount of energy it expends determines the amount of energy it embodies. Bodyweight increases when the amount of energy ingested consistently exceeds that which is expended. Animals expend energy voluntarily and involuntarily. Voluntary energy expenditure is modifiable and susceptible to interventions aimed at attenuating adiposity. Involuntary energy expenditure (i.e. resting energy expenditure, REE) is a constitutional characteristic influenced by innate factors largely resistant to willed alteration and behavioral intervention. It is important therefore to determine the degree to which excess bodyweight is amenable to reduction via the conventional strategies of caloric restriction and exercise. This is especially exigent if segments of a population exhibit significant inherent differences in involuntary energy expenditure, thereby necessitating differing public health recommendations for voluntary energy expenditure. There is support for the supposition that inherent differences in involuntary energy expenditure exist in human popula- tions and may underlie racial and ethnic differences in such anthropometric measures as bodyweight and body composition. Of particular interest in this regard is a study by Sharp [1] and colleagues which sought to assess differences in REE between Blacks and Whites on the basis of indirect calorimetry. The investigators employed $\sim 400$ adult participants evenly distributed by race and gender. Upon controlling for common confounders, they found that REE was $\sim 5 \%$ lower in Blacks compared to Whites. This finding was irrespective of gender or body composition. The authors concluded that REE may not be a major determinant of adiposity or obesity.

That Blacks exhibit lower REE than Whites comports with the conclusion of Luke [2] and colleagues who undertook an extensive review of literature pertaining to racial/ethnic influences on metabolism. They noted that those studies undertaken in this area were mainly conducted in North America and dominated by the discernment of specifically Black/White differences in energy expenditure to the exclusion of other ethnicities. Due to difficulties involved in objectively ascertaining activity energy expenditure, the majority of the studies in question focused exclusively on REE. Females, they found, were 
abundantly represented and, of 26 such studies, 21 found significantly lower REE in Black women upon adjustment for body composition whereas 5 reported no significant differences in REE. Three of the 30 studies involved males - of these, one yielded a null result while the others found Blacks to have REE 5\% lower than Whites. Considering these findings, our study ostensibly improves the present state of knowledge regarding racial/ethnic underpinnings of metabolism in the following respects: 1) Our analysis entails an improved assessment of activity energy expenditure; 2) Inclusion of males and multiple ethnicities remediates the reported underrepresentation of these groups; and 3) Inclusion of a broad age range enables us to ascertain whether any discerned difference in REE is evident over the course of the human lifespan.

The specificity of the relationship between race and metabolism was elucidated by Manini [3] and colleagues who found that, within a group of older Blacks, increasing admixtures of European ancestry were associated with increasing REE. This they determined on the basis of single gene polymorphisms whose proportions diverge significantly by race. Apart from establishing a significant difference in REE between Whites and Blacks $(\sim 160$ $\mathrm{kcal} / \mathrm{d}$ lower in the latter), they found that each percent increase in the proportion of preponderantly Europoid polymorphisms in Blacks corresponded with a $\sim 1 \frac{1}{2}$ $\mathrm{kcal} / \mathrm{d}$ increase in REE.

The present cross-sectional study, which employs nationally representative data, enables us to extrapolate to a sizeable segment of the population and confirm or disconfirm whether races and ethnicities differ in involuntary energy expenditure and whether this difference accords with our theoretical expectations. Our expectations were twofold: 1) that Blacks would exhibit significantly lower REE than Whites and 2) that other ethnicities and self-identified multi-racial individuals would exhibit REE roughly intermediate between that of Blacks and Whites. The latter expectation was based on the simplistic supposition that Asiatic, Hispanic and Polynesian ethnicities as well as multi-racial persons represent a more heterogeneous amalgam of Africoid and Europoid characteristics including heritable metabolic traits.

\section{Race/Ethnicity \& Obesity}

Given our hypothesis that REE differs by race/ethnicity and given the expectation that persons with lower REE will accrete bodyweight more readily, it follows that rates of obesity should be higher in Blacks and other ethnicities relative to Whites. As assessed by body mass index (BMI), obesity is evidently more pervasive among Black Americans and Mexican Americans than White Americans. Using the same dataset (NHANES 2003-2004) employed in the present study, Ogden [4] and colleagues found that whereas approximately $30 \%$ of White adults were obese, $37 \%$ of Mexican American adults, and $45 \%$ of Black adults could be so classified. Among children and adolescents, rates of obesity were generally found to be higher among Mexican Americans, whereas rates between Whites and Blacks did not differ significantly within this age group. Importantly, the investigators did not employ a more direct measure of adiposity (e.g. $\mathrm{X}$-ray absorptiometry) in their analysis as in the present study.

\section{Methods}

Our data were derived from the National Health and Nutrition Examination Survey (NHANES), 2003-2004. NHANES is a continuous compilation of health-related information obtained from non-institutionalized civilian residents of the United States. It employs a complex, probabilistic methodology which ensures adequate, representative sampling of the general population. In each of the current annual phases of NHANES, groups of households are selected from primary sampling units which constitute a subset of all counties in the United States [5]. Demographic information is collected from each individual inhabiting a given household. One individual from each household is selected for inclusion in the study sample. Typically, $\sim 10,000$ individuals $(\sim 80 \%$ of those screened) are subjected to interviews and/or examinations. For the 2003-2004 survey, 12,761 persons were screened; of these, 10,122 persons were interviewed and thereby contributed data to the survey; of these, $79 \%$ underwent one or more of the myriad examinations to which participants are asked to submit [6]. Thus the total un-weighted sample size of the examinees amounted to 9643. Of this number, only a proportion submitted to any given examination or questionnaire. Because our primary dependent variable (REE) was a composite of three distinct variables, each acquired through separate examinations, our final sample size was determined by the number of individuals who contributed complete data to the constituent variables comprising REE. This number amounted to 5134 persons.

\subsection{Demographic Description}

The study subsample $(\mathrm{N}=5134)$ was evenly distributed by gender. Participants ranged in age from $<1$ to $85+$ years. We constructed four age groups: youth/young adult (6 - 19 years); young adult/mature adult (20 - 49 years); mature adult (50 - 69 years); elder adult ( $70-85+$ years). The proportional representation of the racial/ethnic categories was as follows: Mexican Americans, $25 \%$; other Hispanics, $\sim 3 \%$; Whites, $45 \%$; Blacks, $\sim 23 \%$; and Others, $\sim 3 \%$ (see Table 1). Annual household income was 
Table 1. Numerical representation of indicated variables in sample.

\begin{tabular}{|c|c|c|}
\hline Variables & $\mathbf{N}$ & Percent \\
\hline \multicolumn{3}{|l|}{ Race/Ethnicity $(\mathrm{N}=4655)$} \\
\hline Mexican American & 1183 & 25.41 \\
\hline Other Hispanics & 129 & 2.77 \\
\hline Whites & 2112 & 45.37 \\
\hline Blacks & 1058 & 22.73 \\
\hline Others & 173 & 3.72 \\
\hline \multicolumn{3}{|l|}{ Gender $(\mathrm{N}=4655)$} \\
\hline Male & 2323 & 49.90 \\
\hline Female & 2332 & 50.10 \\
\hline \multicolumn{3}{|l|}{$\operatorname{Age}(\mathrm{N}=4655)$} \\
\hline $6-19$ & 1695 & 36.41 \\
\hline $20-49$ & 1341 & 28.81 \\
\hline $50-69$ & 938 & 20.15 \\
\hline 70 - $85+$ & 681 & 14.63 \\
\hline \multicolumn{3}{|l|}{ Total Family Income $(\mathrm{N}=4370)$} \\
\hline$<\$ 20,000$ & 1043 & 23.87 \\
\hline$\$ 20,000-\$ 44,999$ & 1475 & 33.75 \\
\hline$\$ 45,000-\$ 74,999$ & 938 & 21.46 \\
\hline$>\$ 75,000$ & 914 & 20.92 \\
\hline \multicolumn{3}{|l|}{ Education $(\mathrm{N}=4652)$} \\
\hline$<\mathrm{HS}$ & 2345 & 50.41 \\
\hline HS/GED & 802 & 17.24 \\
\hline$>\mathrm{HS}$ & 1505 & 32.35 \\
\hline \multicolumn{3}{|l|}{ Medical History } \\
\hline Thyroid Dysfunction (yes/no) $(\mathrm{N}=2952)$ & $301 / 2651$ & $10.20 / 89.80$ \\
\hline Diabetes $($ yes/no) $(\mathrm{N}=4604)$ & $322 / 4282$ & $6.99 / 93.01$ \\
\hline \multicolumn{3}{|l|}{ Weight Loss History $(\mathrm{N}=3423)$} \\
\hline No & 2828 & 82.62 \\
\hline Yes & 595 & 17.38 \\
\hline
\end{tabular}

categorized into four groups: less than $\$ 20,000 ; \$ 20,000$ - \$44,999; $\$ 45,000$ - \$74,999; and $\$ 75,000$ and greater. Education was classified as less than High School; High School (or equivalent); greater than High School. Data on diabetes were collected from 9645 individuals, of which 559 disclosed a medical diagnosis of diabetes. Data from persons who reported having had a "borderline" diabetic diagnosis $(\mathrm{N}=78)$ or who did not know whether they had ever received a diagnosis of diabetes were not included in the analysis. The number of persons in our subsample from whom data on diabetes were derived amounted to 4604. Data pertaining to pathological conditions of the thyroid gland were collected on 5040 persons. The number of persons in our subsample from whom data on thyroid dysfunction were derived amounted to 2952. Data pertaining to recent, substantial weight loss were collected from individuals aged 16 years and above. Of 6103 such participants, 1049 reported having lost at least 10 pounds in the previous year. These data were employed in the construction of our "weight loss" variable. The number of persons in our subsample from whom data on weight loss were derived amounted to 3423.

Energy intake (EI) was taken to be the quantity of kilocalories reportedly consumed by participants on day 1 of the dietary intake examination. Of 9643 eligible participants, 9373 yielded data on total daily EI. The number of persons in our subsample from whom data on EI were derived amounted to 4655 . Voluntary energy expenditure (VEE) was estimated on the basis of accelerometers worn by participants. Intensity of activity (AIC) was assessed by recording accelerations executed each minute by wearers of the device. A bivariate regression equation developed by A. Yngve and colleagues [7] was used to convert accelerations per minute into metabolic equivalents (METs). The units for METs are kilocalories per kilogram per hour $\left(\mathrm{kcal} \cdot \mathrm{kg}^{-1} \cdot \mathrm{hr}^{-1}\right)$. Using participant bodyweight and converting the unit of time from hour to day (i.e. multiplying METs by kilogram bodyweight and the factor 24), kilocalories expended during voluntary physical activity was deduced. Voluntary energy expenditure data on 5309 individuals was thereby derivable (N $=4655$ ) (see Table 2). An equation that would have yielded a direct estimation of REE- the Harris-Benedict equation-was considered and rejected in consequence of its substantial and significant overestimation of energy expenditure in older African Americans [8]. Further, in contrast to the approach employed in our analysis, the Harris-Benedict equation incorporates neither an estima-

Table 2. Mean and SD of indicated variables in sample.

\begin{tabular}{lrr}
\hline \multicolumn{1}{c}{ Variables } & Mean & \multicolumn{1}{c}{ SD } \\
\hline Anthropometric & & \\
Bodyweight $(\mathrm{Kg})(\mathrm{N}=4655)$ & 70.75 & 23.33 \\
Body Fat $(\mathrm{Kg})(\mathrm{N}=4355)$ & 23.57 & 11.83 \\
Body Fat $(\%)(\mathrm{N}=4355)$ & 33.38 & 9.57 \\
Lean Bodyweight $(\mathrm{Kg})(\mathrm{N}=4355)$ & 48.90 & 13.88 \\
& & \\
Metabolic & & \\
AIC $(\mathrm{N}=4655)$ & 371.86 & 203.60 \\
EI $(\mathrm{Kcal})(\mathrm{N}=4655)$ & 2177.95 & 987.24 \\
METs $(\mathrm{N}=4655)$ & 1.44 & 0.17 \\
VEE $(\mathrm{Kcal})(\mathrm{N}=4655)$ & 2413.68 & 765.75 \\
REE $(\mathrm{Kcal})(\mathrm{N}=4655)$ & -235.73 & 1134.25 \\
\hline
\end{tabular}


tion of EI nor an objective estimation of VEE.

Resting energy expenditure (REE) was taken to be the arithmetic difference between energy intake and voluntary energy expenditure (REE = EI - VEE). In all, 5134 sample participants yielded REE data. This number, encompassing all those individuals from whom complete REE data were derivable, is the basis of our subsample. Body fat content was assessed by dual energy X-ray absorptiometry, a variable to which 7770 sample participants contributed data. The number of persons in our subsample from whom data on body fat content were derived amounted to 4355 .

Graphical analysis revealed VEE (and therefore REE from which it is constructed) to be skewed. Nonparametric tests (e.g. the Kruskal Wallis rank test and Wilcoxon rank-sum test), which do not necessitate the assumptions of normally distributed data, accorded with our results, suggesting that deviations from normality evident in REE and VEE do not undermine our statistical inferences.

\subsection{Measurements}

Physical activity as assessed by accelerometers worn by participants was initiated in the 2003-2004 iteration of NHANES. This measure encompasses data from individuals instructed to wear an Actigraph activity monitor for an interval of seven consecutive days during the diurnal period. The device, worn about the waist, registers "activity counts" when accelerated against gravity in the vertical dimension. These data enable the estimation of VEE when inserted into various published regression equations originated for the purpose [9].

Daily dietary recall of participants is assessed in NHANES by trained interviewers using visual and tactile aides. Collected data are coded in concert with the Food and Nutrient Database for Dietary Studies (FNDDS). The "Nutrient" component of the FNDDS permits quantification of energy intake. Determination of the aforementioned variables (i.e. VEE and EI) permits extrapolation of the dependent variable of interest-REE. Given energy equilibrium - that is, no net weight gain or loss during a defined period - the ratio of energy intake to total energy expenditure equals unity. Total energy expenditure has two principal components moreover-voluntary energy expenditure (VEE) and resting energy expenditure (REE) [10]. Using the following relationship,

$$
\mathrm{EI} /[\mathrm{VEE}+\mathrm{REE}]=1
$$

Resting energy expenditure is deducible thusly:

$$
\mathrm{REE}=\mathrm{EI}-\mathrm{VEE}
$$

\subsection{Validity of Measurements}

Several investigations have assessed the validity of both the NHANES dietary recall method and the Actigraph activity monitor. As to the former, a study compared the NHANES method to what is considered a standard, reliable estimation of total energy expenditure - the doubly labeled water (DLW) technique [11]. The investigators employed $\sim 500$ participants ranging in age from 30 to 69 years. Information on EI was compared with total energy expenditure as assessed by the DLW method. The mean difference between the measures was determined to be $\sim 10 \%$, not reaching statistical significance in the study.

As to the latter measure - physical activity - a study compared energy expenditure as assessed by the Actigraph activity monitor with energy expenditure as assessed by indirect calorimetry [9]. More specifically, the investigators evaluated the degree to which several published regression equations incorporating raw data from the activity monitor approximated energy expenditure relative to calorimetry. Of the three equations evaluated, only one failed to yield results significantly different from calorimetry results. This equation, developed by Yngve and colleagues [7], is what we have employed in our analysis. It is as follows:

$$
\text { METs }=1.136+0.0008249(\mathrm{x})
$$

where METs denote metabolic equivalents expressed in units of energy per unit mass per unit time and $x$ denotes "activity counts", arbitrary units of "acceleration" recorded by the activity monitor.

Body composition data were derived from participants aged 8 years and older with the aid of X-ray absorptiometry. This technique is widely employed in the direct assessment of adiposity. Besides bodyweight (assessed via digital weight scales), other variables of interestannual household income, race/ethnicity, educational attainment, medical history (i.e. of diabetes and thyroid dysfunction), and weight history-were determined via participant self-report.

\subsection{Statistical Analyses}

Statistical analyses were aided by the Stata software package. We employed its svyset command in order to incorporate information regarding NHANES's complex, multi-stage sampling methodology, inclusive of appropriate sample weights. This enabled extrapolation from the study sample to the national population. Descriptive results were expressed in terms of mean and standard deviation, median and inter-quartile range. Correlation analyses were conducted using simple linear regression. Regression results were expressed in terms of beta coefficients, confidence intervals, and p-values. The minimal standard of statistical significance was taken to be $p \leq$ 0.05 . Issues of confounding were addressed principally through regression analysis as those variables most likely to contribute to confounding were included in several 
successive regression models-this approach enabled ascertainment of the influence of these potential confounders on the linear relationship between our main predictor and outcome variables, race/ethnicity and REE respectively.

\section{Results}

\subsection{Anthropometric Indices}

Average bodyweight in the sample under study was $\sim 70$ $( \pm 23)$ kilograms. Of the five racial/ethnic groups-Mexican Americans, other Hispanics, Whites, Blacks and those identified as Other (e.g. Asian Americans, Pacific Islanders, Native Americans) - Blacks had the highest bodyweight $(\sim 78 \pm 1.36 \mathrm{~kg})$ though the difference in bodyweight between Blacks and Whites did not differ significantly $(p=0.329)$ (see Table 3$)$.

Mexican Americans, other Hispanics, and Others exhibited bodyweights significantly lower than Whites $(\mathrm{p}<$ 0.01 ). Body fat percentage was found to be $\sim 33$ percent $( \pm 9.57)$ on average. Females exhibited significantly higher body fat percentages than males $(\sim 40 \% \pm 6.5 \%$ and $\sim 28 \% \pm 6.00 \%$ respectively). Whites were found to have the highest percentage of body fat $(34.60 \% \pm 6.36 \%)$ whereas Blacks exhibited significantly lower body fat percentage than Whites $(33.46 \pm 14.5, \mathrm{p}<0.05)$ (see Table 4).

Adiposity increased significantly with age from a low of $30.35 \% \pm 11.70 \%$ in the age group $6-19$ years to a high of $38.20 \% \pm 8.62 \%$ in the age group $70-85+$ years. Generally, income was found to be inversely associated with body fat percentage: individuals in households with incomes of less than $\$ 20,000 / y r$ exhibited significantly higher body fat percentages than those with incomes exceeding $\$ 45,000 / \mathrm{yr}(\mathrm{p}<0.001)$. Individuals who indicated either a history of thyroid disease or diabetes exhibited significantly greater percentages of body fat than those without these conditions $(\mathrm{p}<0.001)$, while those who reported having lost 5.5 kilograms ( $\sim 10$ pounds) or more in the previous year exhibited significantly greater percentages of body fat than those who had not experi-

Table 3. Descriptive and correlative statistics concerning body weight (BW) in indicated demographic groups.

\begin{tabular}{llc}
\hline \multirow{2}{*}{ Demographic variables } & \multicolumn{2}{c}{ BW (Kg) } \\
\cline { 2 - 3 } & Mean (SD) & p-value \\
\hline Race/Ethnicity $(\mathrm{N}=4655)$ & $68.85(34.19)$ & $<0.001$ \\
Mexican American & $66.32(13.85)$ & $<0.001$ \\
Other Hispanics & $76.69(16.10)$ & - \\
Whites (ref.) & $78.05(35.49)$ & 0.329 \\
Blacks & $66.67(16.47)$ & 0.001 \\
Others & & \\
\hline
\end{tabular}

Table 4. Unadjusted association between body fat percentage (BFP) and categories of indicated independent variables.

\begin{tabular}{|c|c|c|}
\hline \multirow{2}{*}{ Demographic variables } & \multicolumn{2}{|c|}{ BF (\%) } \\
\hline & Mean (SD) & $p$-value \\
\hline \multicolumn{3}{|l|}{ Race/Ethnicity $(\mathrm{N}=4355)$} \\
\hline Mexican American & $33.76(13.47)$ & 0.150 \\
\hline Other Hispanics & $33.17(7.10)$ & 0.156 \\
\hline Whites (ref.) & $34.60(6.36)$ & - \\
\hline Blacks & $33.46(14.50)$ & 0.048 \\
\hline Others & $33.19(6.00)$ & 0.064 \\
\hline \multicolumn{3}{|l|}{ Gender $(\mathrm{N}=4355)$} \\
\hline Male (ref.) & $28.36(5.94)$ & - \\
\hline Female & $40.16(6.47)$ & $<0.001$ \\
\hline \multicolumn{3}{|l|}{$\operatorname{Age}(\mathrm{N}=4355)$} \\
\hline $6-19$ (ref.) & $30.35(11.69)$ & - \\
\hline $20-49$ & $33.40(6.31)$ & $<0.001$ \\
\hline $50-69$ & $36.67(6.87)$ & $<0.001$ \\
\hline $70-85$ & $38.20(8.62)$ & $<0.001$ \\
\hline \multicolumn{3}{|l|}{ Total Family Income $(\mathrm{N}=4084)$} \\
\hline$<\$ 20,000$ (ref.) & $35.66(10.92)$ & - \\
\hline$\$ 20,000-\$ 44,999$ & $35.00(8.68)$ & 0.185 \\
\hline$\$ 45,000-\$ 74,999$ & $34.07(7.57)$ & $<0.001$ \\
\hline$>\$ 75,000$ & $33.04(6.11)$ & $<0.001$ \\
\hline \multicolumn{3}{|l|}{ Education $(\mathrm{N}=4352)$} \\
\hline Less than High School (ref.) & $32.60(12.22)$ & - \\
\hline High School (including GED) & $35.19(8.17)$ & $<0.001$ \\
\hline More than High School & $34.61(7.28)$ & 0.004 \\
\hline \multicolumn{3}{|l|}{ Medical History } \\
\hline \multicolumn{3}{|l|}{ Thyroid Dysfunction $(\mathrm{N}=2848)$} \\
\hline Yes & $39.72(6.24)$ & $<0.001$ \\
\hline No (ref.) & $34.47(7.31)$ & - \\
\hline \multicolumn{3}{|l|}{ Diabetes $(\mathrm{N}=4307)$} \\
\hline Yes & $37.83(8.21)$ & $<0.001$ \\
\hline No (ref.) & $34.00(8.07)$ & - \\
\hline \multicolumn{3}{|l|}{ Weight Loss History $(\mathrm{N}=3307)$} \\
\hline No (ref.) & $34.28(7.73)$ & - \\
\hline Yes & $36.91(7.44)$ & $<0.001$ \\
\hline \multicolumn{3}{|c|}{ enced such weigh loss $(\mathrm{p}<0.001)$} \\
\hline 3.2. Energy Intake & & \\
\hline
\end{tabular}


found to be $\sim 2190( \pm 17)$ kilocalories. No significant differences were discerned between racial/ethnic groups regarding EI (see Table 5). Females consumed $\sim 1880 \pm$ $665 \mathrm{kcal} /$ day, significantly less than the average EI of males, $2629 \pm 976 \mathrm{kcal} /$ day $(\mathrm{p}<0.001)$. EI differed sig-

Table 5. Unadjusted association between energy intake (EI) and categories of indicated independent variables.

\begin{tabular}{|c|c|c|}
\hline \multirow{2}{*}{ Demographic variables } & \multicolumn{2}{|c|}{ EI (kcal) } \\
\hline & Mean (SD) & $p$-value \\
\hline \multicolumn{3}{|l|}{ Race/Ethnicity $(\mathrm{N}=4655)$} \\
\hline Mexican American & $2332.43(1576.64)$ & 0.209 \\
\hline Other Hispanics & $2105.88(675.65)$ & 0.105 \\
\hline Whites (ref.) & $2253.58(695.30)$ & - \\
\hline Blacks & $2181.32(1479.36)$ & 0.174 \\
\hline Others & $2271.45(850.98)$ & 0.848 \\
\hline \multicolumn{3}{|l|}{ Gender $(\mathrm{N}=4655)$} \\
\hline Male (ref.) & $2628.75(976.26)$ & - \\
\hline Female & $1879.50(664.62)$ & $<0.001$ \\
\hline \multicolumn{3}{|l|}{$\operatorname{Age}(\mathrm{N}=4655)$} \\
\hline $6-19$ (ref.) & $2212.27(1301.45)$ & - \\
\hline $20-49$ & $2486.18(889.80)$ & $<0.001$ \\
\hline $50-69$ & $2022.82(777.10)$ & 0.001 \\
\hline $70-85$ & $1689.1(753.32)$ & $<0.001$ \\
\hline \multicolumn{3}{|l|}{ Total Family Income $(\mathrm{N}=4370)$} \\
\hline$<\$ 20,000$ (ref.) & $2137.65(1233.56)$ & - \\
\hline$\$ 20,000-\$ 44,999$ & $2183.53(913.31)$ & 0.413 \\
\hline$\$ 45,000-\$ 74,999$ & $2304.02(788.00)$ & 0.013 \\
\hline$>\$ 75,000$ & $2330.06(731.58)$ & 0.002 \\
\hline \multicolumn{3}{|l|}{ Education $(\mathrm{N}=4652)$} \\
\hline Less than High School (ref.) & $2130.55(1157.43)$ & - \\
\hline High School (including GED) & $2313.65(823.14)$ & 0.003 \\
\hline More than High School & $2292.14(721.12)$ & 0.001 \\
\hline \multicolumn{3}{|l|}{ Medical History } \\
\hline \multicolumn{3}{|l|}{ Thyroid Dysfunction $(\mathrm{N}=4914)$} \\
\hline Yes & $1833.35(648.17)$ & $<0.001$ \\
\hline No (ref.) & $2309.30(842.90)$ & - \\
\hline \multicolumn{3}{|l|}{ Diabetes $(\mathrm{N}=4604)$} \\
\hline Yes & $1910.52(837.19)$ & $<0.001$ \\
\hline No (ref.) & $2277.50(896.65)$ & - \\
\hline \multicolumn{3}{|l|}{ Weight Loss History $(\mathrm{N}=3423)$} \\
\hline No (ref.) & $2305.80(870.08)$ & - \\
\hline Yes & $2096.95(842.04)$ & 0.002 \\
\hline
\end{tabular}

nificantly by age groups, with adults aged 20 - 49 years consuming more and adults aged 50 - 69 years consuming less energy per day than youths aged $6-19$ years $(\mathrm{p}<$ 0.01). EI increased with increasing income, with families earning more than $\$ 45,000 / y r$ consuming more calories per day than those earning less than $\$ 20,000 / y r$ (p < $0.05)$. Education was associated with EI as individuals with a high school education (or its equivalent) and those with more than a high school education consumed a greater quantity of calories per day than those with less than a high school education $(\mathrm{p}<0.01)$. Individuals with diabetes and those having a history of thyroid dysfunction consumed fewer calories per day than individuals devoid of these conditions $(\mathrm{p}<0.001)$. Individuals who reported having lost 5.5 kilograms ( $\sim 10$ pounds) or more in the previous year ingested significantly fewer calories per day than those who had not experienced such weigh loss $(\mathrm{p}=0.002)$.

\subsection{Voluntary Energy Expenditure}

Average voluntary energy expenditure (VEE) in the population was $\sim 2550( \pm 767) \mathrm{kcal} /$ day. Blacks had the highest VEE $(\sim 2670 \pm 1160 \mathrm{kcal} /$ day $)$, significantly higher than Whites $(\mathrm{p}<0.05)$. Others were found to have the lowest VEE $(\sim 2220 \pm 546 \mathrm{kcal} /$ day $)$, significantly lower than Whites $(\mathrm{p}<0.01)$. Average VEE in Whites amounted to $\sim 2580 \pm 535 \mathrm{kcal} /$ day. Mexican Americans and other Hispanics both expended significantly less energy voluntarily than Whites $(\sim 2449 \pm 1210 \mathrm{kcal} /$ day and $\sim 2335 \pm 490 \mathrm{kcal} /$ day respectively, $\mathrm{p}<0.01)$. Males voluntarily expended $\sim 480$ kilocalories more per day than females $(p<0.001)$. VEE was lowest in the youngest age group (6 - 19 years) and highest in the age group $20-49$ years. The oldest age group (70 - 85+ years) voluntarily expended $\sim 2300 \pm 534 \mathrm{kcal} /$ day, significantly more than the youngest age group, whose physical activity amounted to $\sim 1860 \pm 945 \mathrm{kcal} /$ day. VEE increased as household income increased, with the highest income group ( $>$ $\$ 75,000 / y r)$ expending a statistically significant 214 kilocalories more energy voluntarily than the lowest income group $(<\$ 20,000 / y r)$. Individuals with less than a high school education had the lowest VEE whereas individuals with a high school education (or its equivalent) had the highest, a significant $(\mathrm{p}<0.001)$ difference of nearly $600 \mathrm{kcal} /$ day. Individuals with a history of thyroid dysfunction expended significantly fewer calories voluntarily than did those reporting no history of thyroid dysfunction $(\sim 2515 \pm 512 \mathrm{kcal} /$ day vs $\sim 2730 \pm 564 \mathrm{kcal} /$ day, $\mathrm{p}<0.001)$. Individuals with diabetes expended significantly more energy voluntarily than those without diabetes $(\sim 2807 \pm 591 \mathrm{kcal} /$ day vs $\sim 2669 \pm 581 \mathrm{kcal} / \mathrm{day}, \mathrm{p}=$ $0.002)$. Individuals who reported having lost 5.5 kilograms ( $\sim 10$ pounds) or more in the previous year ex- 
pended significantly more energy voluntarily than those who had not experienced such weigh loss $(p=0.001)$.

\subsection{Resting Energy Expenditure}

Resting energy expenditure (REE) was computed by subtracting each participant's voluntary energy expenditure from their energy intake (i.e. REE $=\mathrm{EI}-\mathrm{VEE}$ ). For each age group excepting the youngest ( $6-19$ years), the computation of REE yielded negative mean and/or median values. Mean REE in the population was calculated as $-304.36 \pm 1098.29 \mathrm{kcal} / \mathrm{day}$. Females expended significantly less energy at rest than males, a difference of $\sim 265 \mathrm{kcal} /$ day $(\mathrm{p}<0.001)$. REE generally decreased with age, with the youngest age group exhibiting the highest REE and the penultimate age group (50 - 69 years) exhibiting the lowest REE $(345.33 \pm 1571 \mathrm{kcal} /$ day vs -650 $\pm 830 \mathrm{kcal} /$ day). Diabetics and individuals with a history of thyroid dysfunction expended significantly less energy at rest than those without these conditions $(\mathrm{p}<0.01)$. Individuals who reported having lost 5.5 kilograms $(\sim 10$ pounds) or more in the previous year expended significantly less energy at rest per day than those who had not experienced such weigh loss $(\mathrm{p}<0.001)$.

REE was found to be lowest in Blacks and highest in Others $(-494.15 \pm 1909.39 \mathrm{kcal} /$ day vs. $47.36 \pm 1001.96$ $\mathrm{kcal} /$ day, $\mathrm{p}<0.01$ ) (see Table 6).

Blacks were found to expend 164 fewer $\mathrm{kcal} /$ day at rest than Whites $(p<0.01)$. Mexican Americans were found to expend 211 more $\mathrm{kcal} /$ day than Whites $(\mathrm{p}=$ 0.006). Stratified by age, REE was significantly lower in Blacks than in Whites for each age category excepting the youngest. Upon adjustment for age, gender, education and income (Model I), Blacks were found to expend 308 fewer kcal/day than Whites $(\mathrm{p}<0.001)$ (see Table 7).

Upon additional adjustment for body fat content (Model II, see Table 8), Blacks still exhibited significantly lower REE than Whites $(-235.12 \mathrm{kcal} / \mathrm{day}, \mathrm{p}=0.001)$.

Further adjustment for diabetes and history of thyroid dysfunction (Model III) did not appreciably alter the magnitude or direction of the difference in REE between Blacks and Whites $(-235.39 \mathrm{kcal} / \mathrm{day}, \mathrm{p}<0.001)$. Similarly, additional adjustment for substantial ( $>10$ pounds or 5.5 kilograms) weight loss in the previous year (Model IV) did not appreciably alter the magnitude or direction of the difference in REE between Blacks and Whites $(-237.50 \mathrm{kcal} / \mathrm{day}, \mathrm{p}<0.001)$ (see Tables 9 and 10).

In Regression Model I (adjusted for the aforementioned demographic variables) the group designated as Other exhibited significantly higher REE than Whites $(+328 \mathrm{kcal} /$ day, $\mathrm{p}=0.008)$, though this difference declined to statistical insignificance upon adjustment for body fat, diabetes, thyroid dysfunction, and substantial
Table 6. Unadjusted association between resting energy expenditure (REE, i.e. EI-VEE) and categories of indicated independent variables.

\begin{tabular}{|c|c|c|}
\hline \multirow{2}{*}{ Demographic variables } & \multicolumn{2}{|c|}{ REE (kcal) } \\
\hline & Mean (SD) & $p$-value \\
\hline \multicolumn{3}{|l|}{ Race/Ethnicity $(\mathrm{N}=5134)$} \\
\hline Mexican American & $-116.99(1897.84)$ & 0.006 \\
\hline Other Hispanics & $-228.91(800.78)$ & 0.350 \\
\hline Whites (ref.) & $-327.75(843.58)$ & - \\
\hline Blacks & $-494.15(1909.39)$ & 0.004 \\
\hline Others & $47.36(1001.96)$ & 0.001 \\
\hline \multicolumn{3}{|l|}{ Gender $(\mathrm{N}=5134)$} \\
\hline Male (ref.) & $-169.52(1202.64)$ & - \\
\hline Female & $-453.44(971.43)$ & $<0.001$ \\
\hline \multicolumn{3}{|l|}{ Age $(\mathrm{N}=5134)$} \\
\hline $6-19$ (ref.) & $345.33(1571.09)$ & - \\
\hline $20-49$ & $-298.34(901.59)$ & $<0.001$ \\
\hline $50-69$ & $-650.12(830.03)$ & $<0.001$ \\
\hline $70-85$ & $-614.17(826.93)$ & $<0.001$ \\
\hline \multicolumn{3}{|l|}{ Total Family Income $(\mathrm{N}=4849)$} \\
\hline$<\$ 20,000$ (ref.) & $-259.65(1502.18)$ & - \\
\hline$\$ 20,000-\$ 44,999$ & $-348.82(1123.67)$ & 0.101 \\
\hline$\$ 45,000-\$ 74,999$ & $-300.67(976.62)$ & 0.539 \\
\hline$>\$ 75,000$ & $-281.52(925.38)$ & 0.734 \\
\hline \multicolumn{3}{|l|}{ Education $(\mathrm{N}=5131)$} \\
\hline Less than High School (ref.) & $-25.17(1507.82)$ & - \\
\hline High School (including GED) & $-438.09(937.60)$ & $<0.001$ \\
\hline More than High School & $-415.94(856.12)$ & $<0.001$ \\
\hline \multicolumn{3}{|l|}{ Medical History } \\
\hline \multicolumn{3}{|l|}{ Thyroid Dysfunction $(\mathrm{N}=3431)$} \\
\hline Yes & $-681.67(865.92)$ & 0.004 \\
\hline No (ref.) & $-421.49(1057.68)$ & - \\
\hline \multicolumn{3}{|l|}{ Diabetes $(\mathrm{N}=5083)$} \\
\hline Yes & $-834.82(1045.78)$ & $<0.001$ \\
\hline No (ref.) & $-262.14(1092.78)$ & - \\
\hline \multicolumn{3}{|l|}{ Weight Loss History $(\mathrm{N}=3423)$} \\
\hline No (ref.) & $-363.46(903.06)$ & - \\
\hline Yes & $-710.51(851.32)$ & $<0.001$ \\
\hline
\end{tabular}

weight loss in the previous year.

In order to ascertain whether any interaction existed between race/ethnicity and body fat content, we constructed multiplicative interaction terms as the products 
Table 7. Adjusted association between REE and indicated independent variables, Model I (adjusted for demographic variables).

\begin{tabular}{|c|c|c|}
\hline \multirow{2}{*}{ Covariates } & \multicolumn{2}{|c|}{ Model I (N = 4846) } \\
\hline & $\beta(95 \% \mathbf{C I})$ & $p$-value \\
\hline \multicolumn{3}{|l|}{ Race/Ethnicity } \\
\hline Mex. Amer. & $-41.01(-187.49,105.47)$ & 0.560 \\
\hline Other Hisp. & $-29.41(-250.59,191.77)$ & 0.781 \\
\hline Whites (ref.) & - & - \\
\hline Blacks & $-308.60(-441.79,-175.41)$ & $<0.001$ \\
\hline Others & $327.87(99.49,556.25)$ & 0.008 \\
\hline Gender: Fem. & $-231.33(-338.16,-124.49)$ & $<0.001$ \\
\hline Age & $-333.33(-371.29,-295.37)$ & $<0.001$ \\
\hline Tot. Fam. Inc. & $-28.87(-74.78,17.04)$ & 0.200 \\
\hline Education & $-78.19(-126.57,-29.82)$ & 0.004 \\
\hline BF Content & - & - \\
\hline
\end{tabular}

Table 8. Adjusted association between REE and indicated independent variables, Model II (adjusted for body fat content).

\begin{tabular}{|c|c|c|}
\hline \multirow{2}{*}{ Covariates } & \multicolumn{2}{|c|}{ Model II (N = 4560) } \\
\hline & $\beta(95 \%$ CI $)$ & $p$-val. \\
\hline \multicolumn{3}{|l|}{ Race/Ethnicity } \\
\hline Mex. Amer. & $-47.49(-160.80,65.82)$ & 0.386 \\
\hline Other Hisp. & $-178.20(-424.16,67.76)$ & 0.143 \\
\hline Whites (ref.) & - & - \\
\hline Blacks & $-235.12(-352.54,-117.71)$ & 0.001 \\
\hline Others & $135.01(-53.83,323.86)$ & 0.148 \\
\hline Gender: Fem. & $-1.43(-82.25,79.38)$ & 0.970 \\
\hline Age & $-165.51(-211.89,-119.12)$ & $<0.001$ \\
\hline Tot. Fam. Inc. & $-44.21(-84.75,-3.67)$ & 0.035 \\
\hline Education & $35.73(-2.96,74.42)$ & 0.068 \\
\hline BF Content & $-49.16(-53.23,-45.08)$ & $<0.001$ \\
\hline
\end{tabular}

of these variables. Added to our final regression model, these interaction terms were not found to be significant. To ascertain whether any selection bias existed in the selection of participants, we determined the maximum number of participants eligible for the analyses from which the REE construct was derived (i.e. EI and VEE).
Table 9. Adjusted association between REE and indicated independent variables, Model III (Model II adjusted for diabetes and thyroid dysfunction).

\begin{tabular}{|c|c|c|}
\hline \multirow{2}{*}{ Covariates } & \multicolumn{2}{|c|}{ Model III (N = 3116) } \\
\hline & $\beta(95 \% \mathbf{C I})$ & $p$-value \\
\hline \multicolumn{3}{|l|}{ Race/Ethnicity } \\
\hline Mex. Amer. & $-69.60(-210.47,71.26)$ & 0.309 \\
\hline Other Hisp. & $-150.46(-413.88,112.96)$ & 0.242 \\
\hline Whites (ref.) & - & - \\
\hline Blacks & $-235.39(-339.23,-131.55)$ & $<0.001$ \\
\hline Others & $121.94(-97.05,340.93)$ & 0.254 \\
\hline Gender: Fem. & $20.06(-74.96,115.08)$ & 0.659 \\
\hline Age & $-173.60(-243.61,-103.59)$ & $<0.001$ \\
\hline Tot. Fam. Inc. & $-61.32(-106.55,-16.09)$ & 0.011 \\
\hline Education & $31.65(-13.74,77.03)$ & 0.158 \\
\hline BF content & $-46.38(-50.69,-42.08)$ & $<0.001$ \\
\hline Diabetes & $89.37(-30.68,209.41)$ & 0.133 \\
\hline Thyr. Dysf. & $70.30(-40.69,181.30)$ & 0.197 \\
\hline Weight Loss & - & - \\
\hline
\end{tabular}

This number was determined to be 4866 . Of this number, 211 persons did not contribute REE data. Values for several variables of interest were compared between the two groups. Age differences were found to be statistically insignificant $(p=0.2751)$ whereas gender differences were found to be marginally significant $(p=0.0447)$. A significant difference was found in the relative representation of races/ethnicities $(p=0.0169)$ whereas no significant differences were found in education or income $(\mathrm{p}$ $=0.2599$ and $\mathrm{p}=0.1553$ respectively).

\section{Discussion}

In accordance with our expectation, we confirmed that REE is significantly lower in Black Americans, this difference being relative to the general populace, to Whites, to Mexican Americans, to Hispanic Americans, and, collectively, to the other ethnicities extant in the non-institutionalized population of the United States over the span of time encompassed by our investigation. This difference was discernible in each age category, reaching statistical significance in all but the youngest category. Interestingly, the magnitude of the unadjusted difference we discerned $(\sim 160 \mathrm{kcal} /$ day $)$ is comparable to that 
Table 10. Adjusted association between REE and indicated independent variables, Model IV (Model III adjusted for weight loss in previous year).

\begin{tabular}{|c|c|c|}
\hline \multirow{2}{*}{ Covariates } & \multicolumn{2}{|c|}{ Model IV (N = 3088) } \\
\hline & $\beta(95 \% \mathbf{C I})$ & $p$-value \\
\hline \multicolumn{3}{|l|}{ Race/Ethnicity } \\
\hline Mex. Amer. & $-66.83(-203.09,69.44)$ & 0.312 \\
\hline Other Hisp. & $-153.22(-411.78,105.33)$ & 0.226 \\
\hline Whites (ref.) & - & - \\
\hline Blacks & $-237.50(-342.68,-132.32)$ & $<0.001$ \\
\hline Others & $121.28(-99.43,341.99)$ & 0.260 \\
\hline Gender: Fem. & $20.59(-72.44,113.63)$ & 0.644 \\
\hline Age & $-180.11(-252.44,-107.78)$ & $<0.001$ \\
\hline Tot. Fam. Inc. & $-66.86(-112.07,-21.64)$ & 0.007 \\
\hline Education & $29.71(-20.01,79.42)$ & 0.222 \\
\hline BF content & $-45.62(-49.89,-41.34)$ & $<0.001$ \\
\hline Diabetes & $72.83(-47.87,193.53)$ & 0.218 \\
\hline Thyr. Dysf. & $68.53(-40.48,177.54)$ & 0.200 \\
\hline Weight Loss & $-162.45(-253.38,-71.53)$ & 0.002 \\
\hline
\end{tabular}

observed by Manini [3] and colleagues who employed indirect calorimetry in their assessment of racial differences in REE as discussed above. Considering those demographic characteristics which commonly contribute to confounding - age, gender, income, and educationthese variables were included in our initial regression model (Model I). Controlling for these variables increased the magnitude of the difference in REE between Blacks and Whites and augmented the statistical significance of that difference. Considering the fact that fat is less metabolically active than muscle and might moderate the relationship between race/ethnicity and REE, we included body fat content in the subsequent regression model (Model II). Though reduced in magnitude, significantly lower REE in Blacks remained. Considering the fact that certain medical conditions can cause metabolic fluctuations, we endeavored to control for those conditions commonly known to influence metabolic rate - e.g. diabetes and thyroid dysfunction (Model III). Adjusting for these disorders did not appreciably alter the magnitude or significance of the difference in REE between Blacks and Whites. Considering the fact that weight loss indicates energy imbalance, we sought to account for its effects by incorporating a "weight loss" variable in the subsequent model (Model IV). Adjusting for weight loss did not appreciably alter the magnitude or significance of the difference in REE between Blacks and Whites. Contrary to our secondary hypothesis, we did not find statistically significant differences in REE between Mexican Americans, other Hispanics, and Others relative to Whites in Models II - IV (i.e. adjusted for customary confounders, body fat, diabetes, thyroid dysfunction, and recent weight loss).

Our analysis revealed that energy intake did not differ significantly by race/ethnicity. Expectedly, males consumed considerably more calories per day than females. Interestingly, energy intake increased with increasing income, a finding suggestive of a link between affluence and indulgence. EI was also associated with educational attainment as those with a high school education and above consumed more calories per day than those with less than a high school education. EI was also significantly lower in individuals with diabetes and individuals with a history of thyroid dysfunction. So too did persons who lost more than 10 pounds in the previous year consume significantly fewer calories per day than those who had not.

We found that race/ethnicity was associated with voluntary energy expenditure. Whereas Blacks apparently engaged in significantly more physical activity than Whites, Mexican Americans, other Hispanics, and Others engaged in significantly less physical activity than Whites. Females were found to expend significantly less energy voluntarily than males. Interestingly, individuals in the youngest age category were found to have the lowest VEE, significantly lower than even the oldest age group. VEE was found to decrease with decreasing income. Those whose educational attainment exceeded the high school level exhibited significantly higher levels of physical activity than those with less than a high school education. Whereas individuals with diabetes expended significantly more energy voluntarily than those without diabetes, individuals with a history of thyroid dysfunction expended significantly less energy voluntarily than those without a history of thyroid dysfunction. Expectedly, individuals who experienced substantial weight loss in the previous year engaged in significantly more physical activity than those who did not experience such weight loss.

In keeping with expectations, females expended significantly less energy at rest than males. This finding is likely attributable to proportionately lower levels of lean body tissue in females as our Model II regression analysis revealed no significant effect of gender on REE when adjusted for body fat content in the presence of the other included variables. Also consonant with expectations was the general trend of decreasing REE with increasing age, the eldest age group expending 600 
kilocalories fewer at rest per day than the youngest age category. Diabetes and thyroid disease were both associated with reduced REE. Expectedly, individuals having experienced substantial weight loss in the previous year expended significantly less energy at rest than those who had not experienced such weight loss.

Apart from purely statistical significance, the magnitude ( $235-300 \mathrm{kcal} / \mathrm{day})$ of the deficit in REE among Blacks is sufficiently large to be of practical importance. A few hundred kilocalories per day amounts to an appreciable proportion $(0.15)$ of a standard $2000 \mathrm{kcal} /$ day diet (US HHS, USDA, 2005). Collectively and conceptually, given equal energy intakes Blacks would need to expend significantly more energy voluntarily than Whites in order to maintain an average bodyweight comparable thereto. Indeed, we found that EI among Blacks and Whites was statistically equivalent as was bodyweight. Further, we found that Blacks expended significantly more energy voluntarily than Whites. Thus, it is apparent that the deficit in REE among Blacks is offset by an increment in VEE, which results in an equivalent energy/mass constitution (i.e. bodyweight) in Blacks and Whites. It is also apparent that the deficit in REE does not seemingly contribute to increased adiposity in Blacks as they exhibited significantly lower body fat percentage than Whites. Moreover, given that obesity is often defined in terms of body mass index (BMI) and given that BMI is intended as a proxy for adiposity, it is possible that this widely employed index is a comparatively poor indicator of obesity $[12,13]$, at least in Blacks. In this respect it should be considered that body fat percentage in the present study was based on data derived from dual energy $\mathrm{X}$-ray absorptiometry whereas BMI is simply a ratio of weight to the square of height. The former method imparts information regarding the body's actual composition, the latter does not.

\section{Public Health Implications}

Our findings suggest that Blacks, in comparison to the general populace, may incur an inherent impediment in attempting to lose weight insofar as they expend less energy at rest. To the extent that lower average bodyweight is a desirable public health aim to advance among Black Americans, the following points warrant reflection in the context of our results. First, it can be inferred from our investigation that, among Blacks, factors other than obesity may explain increased susceptibility to metabolically mediated medical conditions (e.g. diabetes, hypertension, cardiovascular disease, etc.). To the extent that rates of such conditions differ by race, obesity cannot be considered the principal causative agent insofar as Blacks exhibit lower adiposity than Whites as indicated by X-ray absorptiometry. Alternatively, environmental influences and psycho-social stressors such as racism, poverty, and violence may be postulated to play a prominent part in predisposing Blacks to certain chronic conditions that are commonly considered to be associated with obesity. Moreover, our findings indicate that Blacks expend more energy voluntarily whilst ingesting a quantity of calories equivalent to that of Whites. Thus, public health recommendations tailored to Blacks would need to encourage higher levels of physical activity than partaken by the general populace and/or restricting caloric intake below the level extant in the general populace. In short, Blacks would need to be more restrictive in their caloric intake than the average American or even more physically active than the average American in order to reduce their bodyweight below that of the average American. Such increased metabolic requirements placed upon Blacks result from factors that are largely immutable. Despite the difficulty that this phenomenon presents for public health practitioners and theorists, insight provided by this study into the nature of the issue should enable us to address the obesity epidemic more effectively

\section{REFERENCES}

[1] T. A. Sharp, M. L. Bell, G. K. Grunwald, K. H. Schmitz, S. Sidney, C. E. Lewis, K. Tolan and J. O. Hill, "Differences in Resting Metabolic Rate Between White and African-American Young Adults," Obesity Research, Vol. 10, No. 8, 2002, pp. 726-732.

[2] A. Luke, L. Dugas and H. Kramer, "Ethnicity, Energy Expenditure and Obesity: Are the Observed Black/White Differences Meaningful?" Current Opinions in Endocrinology, Diabetes \& Obesity, Vol. 14, No. 5, 2007, pp. 370-373.

[3] T. M. Manini, K. V. Patel, D. C. Bauer, E. Ziv, D. A. Schoeler, D. C. Mackey, R. Li, A. B. Newman, M. Nalls, J. M. Zmuda and T. B. Harris, "European Ancestry and Resting Metabolic Rate in Older African Americans," European Journal of Clinical Nutrition, Vol. 65, No. 6, 2011, pp. 663-667.

[4] C. L. Ogden, M. D. Carroll, L. R. Curtin, M. A. McDowell, C. J. Tabak and K. M. Flegal, "Prevalence of Overweight and Obesity in the United States, 1999-2004," Journal of the American Medical Association, Vol. 295, No. 13, 2006, pp. 1549-1555.

[5] Centers for Disease Control and Prevention (CDC), National Center for Health Statistics (NCHS), National Health and Nutrition Examination Survey Questionnaire, "Analytic and Reporting Guidelines," US Department of Health and Human Services, Centers for Disease Control and Prevention, Hyattsville, 2008.

http://www.cdc.gov/nchs/about/major/nhanes/nhanes2003 -2004/analytical guidelines.htm

[6] “2003-2004 NHANES Response Rates,” 2011. http://www.cdc.gov/nchs/data/nhanes/response_rates_cps/ RRT0304MF.pdf

[7] A. Yngve, A. Nilsson, M. Sjostrom and U. Ekelund, "Effect of Monitor Placement and of Activity Setting on the 
MTI Accelerometer Output," Medical Science, Sports \& Exercise, Vol. 35, No. 2, 2003, pp. 320-326.

[8] C. Compher, R. Cato, J. Bader and B. Kinosian, "Harris-Benedict Equations Do Not Adequately Predict Energy Requirements in Elderly Hospitalized African Americans," Journal of the National Medical Association, Vol. 96, No. 2, 2004, pp. 209-214.

[9] M. P. Rothney, E. V. Schaefer, M. M. Neumann, L. Choi and K. Y. Chen, "Validity of Physical Activity Intensity Predictions by Actigraph, Actical, and RT3 Accelerometers," Obesity, Vol. 16, No. 8, 2008, pp. 1946-1952.

[10] A. C. Guyton and J. E. Hall, "Textbook of Medical Physiology," 11th Edition, Elsevier Saunders, Philadelphia, 2006.

[11] A. J. Moshfegh, D. G. Rhodes, D. J. Baer, T. Murayi, J. C.
Clemens, W. V. Rumpler, D. R. Paul, R. S. Sebastian, K. J. Kuczynski, L. A. Ingwersen, R. C. Staples and L. E. Clevland, "The US Department of Agriculture Automated Multiple-Pass Method Reduces Bias in the Collection of Energy Intakes," American Journal of Clinical Nutrition, Vol. 88, No. 2, 2008, pp. 324-332.

[12] R. N. Bergman, D. Stefanovski, T. A. Buchanan, A. E. Sumner, J. C. Reynolds, N. G. Sebring, A. H. Xiang and R. M. Watanabe, "A Better Index of Body Adiposity," Obesity (Silver Spring), Vol. 19, No. 5, 2011, pp. 1083 1089.

[13] N. M. Byrne, A. P. Hills, G. R. Hunter, R. L. Weinsier and Y. Schutz, "Metabolic Equivalent: One Size Does Not Fit All," Journal of Applied Physiology, Vol. 99, No. 3, 2005, pp. 1112-1119. 